Check for updates

Cite this: RSC Adv., 2017, 7, 48958

Received 10th July 2017

Accepted 21st September 2017

DOI: 10.1039/c7ra07579k

rsc.li/rsc-advances

\section{Enhancing the performance and stability of carbon- based perovskite solar cells by the cold isostatic pressing method $\dagger$}

\author{
Yangwen Zhang, ${ }^{a}$ Jize Wang, ${ }^{a}$ Xue Liu, ${ }^{a}$ Wangnan Li, ${ }^{b}$ Fuzhi Huang, ${ }^{a}$ Yong Peng, ${ }^{a}$ \\ Jie Zhong, (D) ${ }^{a}$ Yibing Cheng (D) ac and Zhiliang Ku (D) *a
}

The cold isostatic pressing method was used as a post-treatment process for enhancing the power conversion efficiency and stability of carbon-based perovskite solar cells without hole transport materials.
In the past few years, organic-inorganic hybrid lead halide perovskite solar cells (PSCs) have demonstrated enormous potential for next generation photovoltaics because of their ease and low cost of fabrication in combination with high power conversion efficiency (PCE). In fact, solar cells employing solution-processed hybrid perovskite materials as light absorbers have surpassed $22 \%$ PCE, ${ }^{1}$ which is on a par with the most mature photovoltaic (PV) technologies (multi-crystalline $\mathrm{Si}, 21.3 \%$ ). Nevertheless, PSCs still need to surmount challenges to their stability, low cost, reproducibility and industrial scaling-up before they can enter the pantheon of breakthrough commercial PV technologies. Therefore, several strategies ${ }^{2-10}$ have been developed by integrating these solution-processed perovskite compounds to address the aforementioned issues. Among these strategies, carbon-based PSCs have received wide attention by many research groups ${ }^{11-16}$ since the first report in $2013 .{ }^{10}$ In comparison to other types of PSCs, carbon-based PSCs without hole-transport materials (HTM) take full advantage of the superior properties of perovskite-type absorbers such as long charge carrier diffusion length and high mobility. ${ }^{17-19} \mathrm{In}$ this case, the non-use of HTM can save the material expense, simplify the fabrication procedures and enhance the stability of PSCs. More importantly, carbon-based PSCs without HTM can be fabricated by full-printing process, which would be of great benefit to scale up the solar devices for commercial applications. However, like anything else, the carbon electrodes have their shortcomings such as low-conductivity and loose porous

${ }^{a}$ State Key Laboratory of Advanced Technologies for Materials Synthesis and Processing, International School of Materials Science and Engineering, Wuhan University of Technology, 122 Luoshi Road, Wuhan, Hubei, P. R. China. E-mail: zhiliang.ku@whut.edu.cn

${ }^{b}$ Hubei Key Laboratory of Low Dimensional Optoelectronic Material and Devices, Hubei University of Arts and Science, 296 Longzhong Road, Xiangyang, Hubei Province, P. R. China

'Department of Materials Science and Engineering, Monash University, Wellington Road, Clayton, VIC 3800, Australia

$\dagger$ Electronic supplementary information (ESI) available: Experimental details, IPCE of the champion device. See DOI: 10.1039/c7ra07579k structure. Typically, the thickness of carbon electrode was controlled at about $10 \mu \mathrm{m}$ to ensure conductivity and properly filtration of perovskite precursor. Hence, high cell resistance along with uncontrolled crystallization of the perovskite precursor solution in carbon-based PSCs are the limiting factors for their further development. ${ }^{10,20}$ At this point, some specific and innovative strategies must be employed to address the above problem.

Based on our previous experience, ${ }^{21,22}$ cold isostatic pressing (CIP) can be used to compress the mesoporous $\mathrm{TiO}_{2}$ beads to obtain good connection between the beads. Since the carbonbased PSCs have similar mesoporous structure to the $\mathrm{TiO}_{2}$ beads, we believe that CIP could have positive effect on reducing the overall resistance of the cell. In this work, we employed CIP as a post treatment for carbon-based PSCs. The results showed that this CIP treatment can not only enhance the compactness of the porous layers, but also provides a pathway to fabricate high performance carbon-based PSCs with high humidity resistance. The carbon-based PSCs were fabricated by the procedures reported previously. ${ }^{23}$ Briefly, $\mathrm{TiO}_{2}$ compact layer was firstly deposited on FTO substrate by aerosol spray pyrolysis method. Then, $\mathrm{TiO}_{2}, \mathrm{ZrO}_{2}$ and carbon mesoporous films were successively deposited on the $\mathrm{TiO}_{2}$ compact layer (see Fig. 1a). Afterwards, $\mathrm{FA}_{x} \mathrm{MA}_{1-x} \mathrm{PbI}_{3}$ perovskite was loaded by immersing the as-prepared films filled with $\mathrm{PbI}_{2}$ in FAI/MAI $(0.79: 0.21$ in mole ratio) 2-propanol solution, known as "two-step" method. ${ }^{24}$ Finally, the prepared devices were encapsulated in vacuum, followed by cold isostatic pressing under different pressure (Fig. 1c, see ESI for more details $\dagger$ ). In these devices, both $\mathrm{MAPbI}_{3}$ and $\mathrm{FAPbI}_{3}$ perovskite can harvest light and generate photoelectrons, which could be collected by mesoporous $\mathrm{TiO}_{2}$ layer. Meanwhile, the corresponding holes at their valence band were collected by carbon counter electrode, forming photocurrent (energy level diagram is presented in Fig. 1b).

XRD measurement was used to identify the $\mathrm{FA}_{x} \mathrm{MA}_{1-x} \mathrm{PbI}_{3}$ perovskite in the device. As shown in Fig. 2, the XRD pattern of the blank $\mathrm{TiO}_{2} / \mathrm{ZrO}_{2} /$ carbon film has a strong peak at $26.3^{\circ}$, 


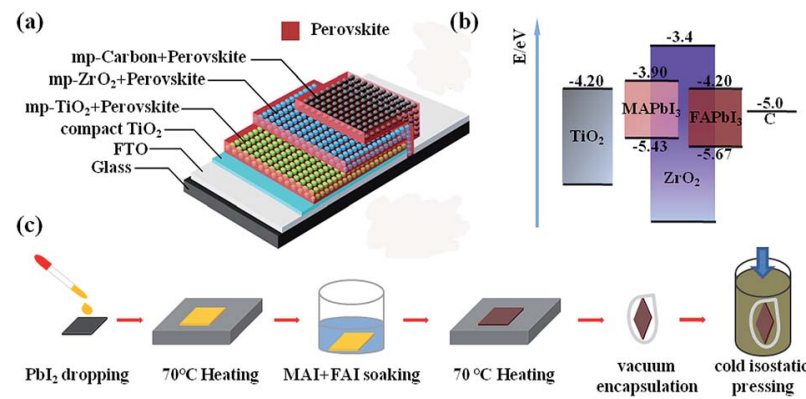

Fig. 1 (a) The schematic structure of the fully printable mesoscopic perovskite solar cell with carbon counter electrode; (b) the energy level diagram (relative to vacuum) of the pure perovskites, $\mathrm{MAPbl}_{3}$ and $\mathrm{FAPbl}_{3}$; (c) the schematic diagram of two-step deposition method, followed by vacuum encapsulation and CIP procedure.

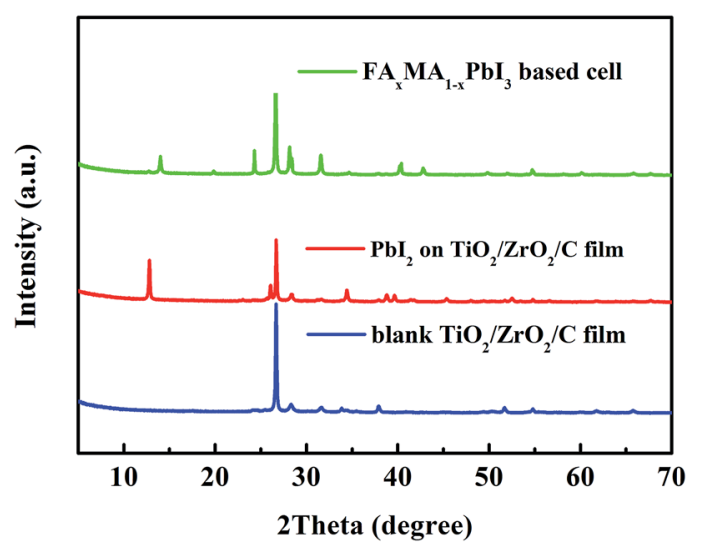

Fig. 2 The XRD spectra of the blank $\mathrm{TiO}_{2} / \mathrm{ZrO}_{2} /$ carbon film and $\mathrm{Pbl}_{2}$ in the $\mathrm{TiO}_{2} / \mathrm{ZrO}_{2} /$ carbon film, and the $\mathrm{FA}_{x} \mathrm{MA}_{1-x} \mathrm{Pbl}_{3}$ based cell.

which should be indexed to (002) reflection of graphite. After the loading of $\mathrm{PbI}_{2}$, new peaks emerged at $12.6^{\circ}, 25.9^{\circ}, 34.2^{\circ}$ and $39.7^{\circ}$, corresponding to the characteristic peaks of $\mathrm{PbI}_{2}$. By immersing in FAI/MAI solution, nearly all the $\mathrm{PbI}_{2}$ converted to $\mathrm{FA}_{x} \mathrm{MA}_{1-x} \mathrm{PbI}_{3}$ perovskite. The peaks emerging at $14^{\circ}$, $28^{\circ}$ and $31.4^{\circ}$ are similar with that of tetragonal $\mathrm{MAPbI}_{3}$, indicating $\mathrm{FA}_{x} \mathrm{MA}_{1-x} \mathrm{PbI}_{3}$ with trigonal symmetry (P3m1) has been synthesised (green line). Note that, no obvious $\sigma-\mathrm{FAPbI}_{3}$ (yellow phase) peaks can be find in the spectra of the $\mathrm{FA}_{x} \mathrm{MA}_{1-x} \mathrm{PbI}_{3}$ based cell, attributing to the stabilizing effect from MAI. ${ }^{25}$

Interestingly, seen from the front side, all of the active area became darker after the treatment of CIP (inset, Fig. 3). The microstructure of these devices was characterized by scanning electron microscopy (SEM) from cross section. Before CIP treatment, we can clearly see the carbon layer, composed of flaky graphite and small carbon black particles, shows loose and porous morphology with the thickness of $10 \mu \mathrm{m}$ (Fig. 3a). However, after CIP treatment, all of the three layers were compressed and it's hard for us to identify the boundaries (Fig. 3a). This will help the holes transfer from perovskite to carbon and as a result, reduce the overall cell resistance $\left(R_{\text {cell }}\right)$.

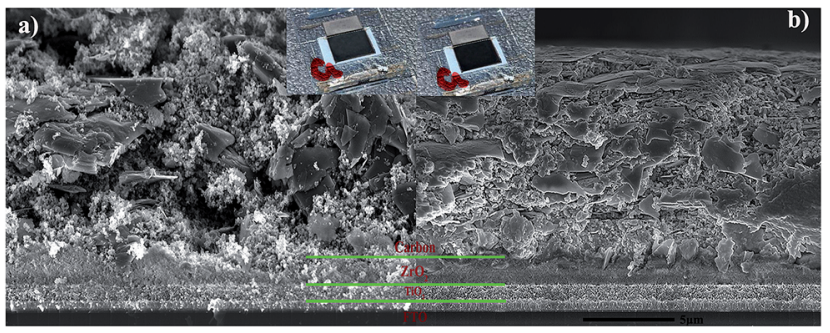

Fig. 3 SEM images from the cross section and optical photographs (inset) of the $\mathrm{FA}_{x} \mathrm{MA}_{1-x} \mathrm{Pbl}_{3}$ based cells (a) before and (b) after CIP treatment.

To confirm this, the photovoltaic performance of the devices (4 groups, each group consist of 8 cells chosen randomly from 32 cells) treated by CIP method with different pressures ( $0 \mathrm{MPa}$, $75 \mathrm{MPa}, 150 \mathrm{MPa}$ and $225 \mathrm{MPa}$ ) was characterized. As summarized in Fig. 4, without treatment ( $0 \mathrm{MPa}$ ), the first group of cells exhibit an average short-circuit current density ( $\operatorname{avg}-J_{\mathrm{sc}}$ ) of $19.1 \mathrm{~mA} \mathrm{~cm}{ }^{-2}$, open-circuit voltage (avg- $V_{\text {oc }}$ ) of $879 \mathrm{mV}$ and average fill factor (avg-FF) of 0.53 , yielding average power conversion efficiency (avg-PCE) of 9.01\%. The second ( $75 \mathrm{MPa}$ ) and third (150 MPa) group of cells have similar avg $-J_{\mathrm{sc}}$ with that of the first group and have a slight improvement in avg- $V_{\mathrm{oc}}$. However, the avg-FF of the devices grew significantly as the increase of pressure, indicating better charge transfer in mesoporous films. The last group of cells treated by CIP at $225 \mathrm{MPa}$ possess the worst photovoltaic parameters, which should ascribe the damage of device at excessively high pressure. Taken together, the device treated by CIP at $150 \mathrm{MPa}$ (marked as $\mathrm{CIP}_{150}$ ) have best performance (avg-PCE $=11.1 \%$ ).

$J-V$ curves of the champion cell before and after the $\mathrm{CIP}_{150}$ treatment are shown in Fig. 5. After CIP $_{150}$ procedure, the value of $R_{\text {cell }}$ determined by the slope of the curve dropped from $17.2 \Omega$ to $8.9 \Omega$, rendering higher FF. PCE of the cell increased from $9.10 \%$ to $11.6 \%$, with growth of $27 \%$.

Long-term stability of the cells without encapsulation was tested at $25^{\circ} \mathrm{C}$ and $50 \%$ relative humidity (Fig. 6). After $1000 \mathrm{~h}$,
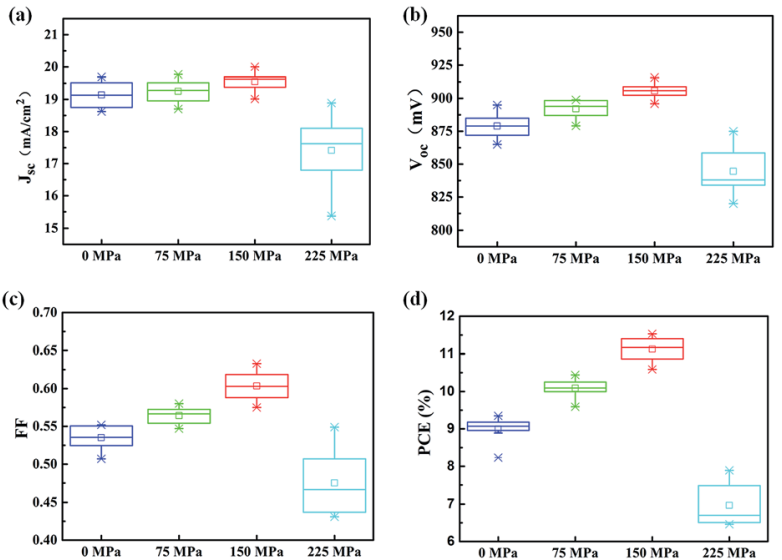

Fig. 4 Photovoltaic parameters of 4 groups of cells (each group include 8 cells) treated by CIP with different pressures. 


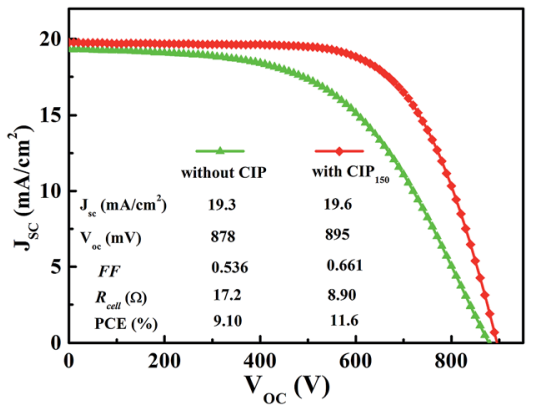

Fig. 5 The J-V curves of the champion cell measured under AM 1.5G illumination.
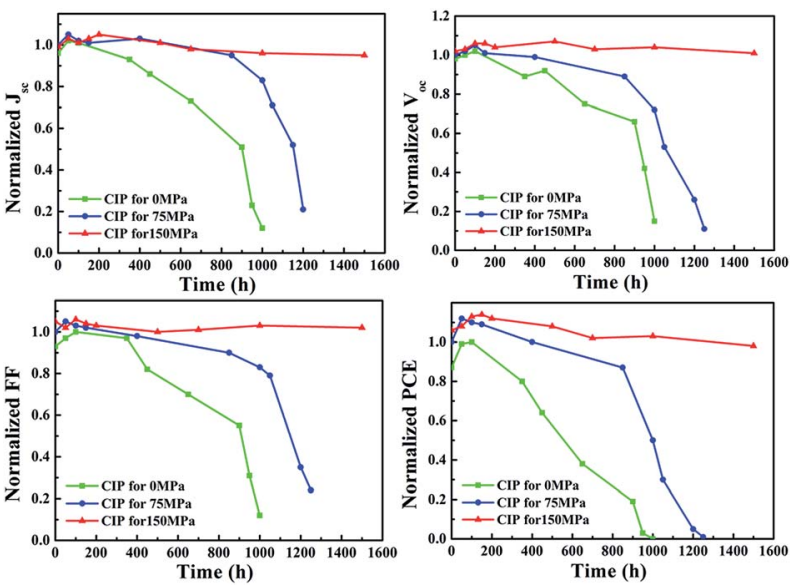

Fig. 6 Stability data of the cells treated by CIP with different pressures.

the cell without CIP treatment almost lost all of its performance. However, the cell treated by $\mathrm{CIP}_{75}$ maintained $85 \%$ of its initial PCE after $1000 \mathrm{~h}$, but decayed quickly in the next $200 \mathrm{~h}$. Surprisingly, the performance parameters of the cell treated by $\mathrm{CIP}_{150}$ have no obvious degradation even after $1500 \mathrm{~h}$.

The good stability of the CIP-treated cells in humidity should attribute to the compact surface of the cell. To confirm this, contact-angle measurements were conducted on the carbon layer on top of the cells (see Fig. 7). Without CIP treatment, the carbon layer filled with perovskite showed a contact angle of $60^{\circ}$ to water. However, by using CIP treatment, the value of contact angle goes up with increasing pressure. As we can imagine, with more compact structure and larger contact angle to water, the carbon/perovskite layer on top of cell will offers better protection against moisture, and eventually, improves stability.

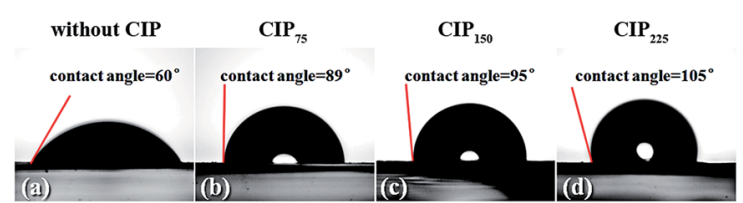

Fig. 7 Optical images of contact-angle measurement for the PSC device treated by CIP with different pressures.

\section{Conclusions}

In sum, cold isostatic pressing (CIP) method was used for enhancing the performance of hole-conductor-free perovskite solar cells with a triple-layer structure $\left(\mathrm{TiO}_{2} / \mathrm{ZrO}_{2} /\right.$ carbon $)$. After CIP process, the mesoporous films filling with perovskite absorber were pinched by the pressure and thus have high compactness. Hence, the charge transport resistance of the solar device can be reduced and moisture can also be blocked by the compact carbon layer. As a result, the champion solar cell enhanced its efficiency from $9.10 \%$ to $11.6 \%$ via CIP process and showed superior stability $(1500 \mathrm{~h})$ in $50 \%$ relative humidity circumstance.

\section{Conflicts of interest}

There are no conflict to declare.

\section{Acknowledgements}

The authors acknowledge the financial support by National Natural Science Foundation of China (NSFC 51402115, 51672202, 51702243), Hubei Provincial Natural Science Foundation of China (2016CFB464), The Technological Innovation Key Project of Hubei Province (2016AAA041), The Fundamental Research Funds for the Central Universities (WUT: 2016IVA093, 2016IVA089, 2016IVA 085, 2016III030, 2017III022) and Hubei Key Laboratory of Low Dimensional Optoelectronic Material and Devices (HLOM151001).

\section{Notes and references}

1 N. R. E. L. N. Best Research Cell_Efficiencies, April 14 2017, https://www.nrel.gov/pv/assets/images/efficiency-chart.png.

2 T. Leijtens, G. E. Eperon, S. Pathak, A. Abate, M. M. Lee and H. J. Snaith, Nat. Commun., 2013, 4, 2885.

3 Q. Tai, P. You, H. Sang, Z. Liu, C. Hu, H. L. W. Chan and F. Yan, Nat. Commun., 2016, 7, 11105.

4 F. Bella, G. Griffini, J.-P. Correa-Baena, G. Saracco, M. Grätzel, A. Hagfeldt, S. Turri and C. Gerbaldi, Science, 2016, DOI: $10.1126 /$ science.aah4046.

5 H. Tan, A. Jain, O. Voznyy, X. Lan, F. P. García de Arquer, J. Z. Fan, R. Quintero-Bermudez, M. Yuan, B. Zhang, Y. Zhao, F. Fan, P. Li, L. N. Quan, Y. Zhao, Z.-H. Lu, Z. Yang, S. Hoogland and E. H. Sargent, Science, 2017, DOI: 10.1126/science.aai9081.

6 K. A. Bush, A. F. Palmstrom, Z. J. Yu, M. Boccard, R. Cheacharoen, J. P. Mailoa, D. P. McMeekin, R. L. Z. Hoye, C. D. Bailie, T. Leijtens, I. M. Peters, M. C. Minichetti, N. Rolston, R. Prasanna, S. Sofia, D. Harwood, W. Ma, F. Moghadam, H. J. Snaith, T. Buonassisi, Z. C. Holman, S. F. Bent and M. D. McGehee, Nat. Energy, 2017, 2, 17009.

7 A. Mei, X. Li, L. Liu, Z. Ku, T. Liu, Y. Rong, M. Xu, M. Hu, J. Chen, Y. Yang, M. Gratzel and H. Han, Science, 2014, 345, 295-298. 
8 M. Yang, Z. Li, M. O. Reese, O. G. Reid, D. H. Kim, S. Siol, T. R. Klein, Y. Yan, J. J. Berry, M. F. A. M. van Hest and K. Zhu, Nat. Energy, 2017, 2, 17038.

9 Y. Wu, X. Yang, W. Chen, Y. Yue, M. Cai, F. Xie, E. Bi, A. Islam and L. Han, Nat. Energy, 2016, 1, 16148.

10 Z. Ku, Y. Rong, M. Xu, T. Liu and H. Han, Sci. Rep., 2013, 3, 3132.

11 T. A. N. Peiris, A. K. Baranwal, H. Kanda, S. Fukumoto, S. Kanaya, L. Cojocaru, T. Bessho, T. Miyasaka, H. Segawa and S. Ito, Nanoscale, 2017, 9, 5475-5482.

12 X. Zheng, H. Chen, Q. Li, Y. Yang, Z. Wei, Y. Bai, Y. Qiu, D. Zhou, K. S. Wong and S. Yang, Nano Lett., 2017, 17, 2496-2505.

13 S. Liu, K. Cao, H. Li, J. Song, J. Han, Y. Shen and M. Wang, Sol. Energy, 2017, 144, 158-165.

14 N. Cheng, P. Liu, F. Qi, Y. Xiao, W. Yu, Z. Yu, W. Liu, S.-S. Guo and X.-Z. Zhao, J. Power Sources, 2016, 332, 24-29. 15 J. Liang, C. Wang, Y. Wang, Z. Xu, Z. Lu, Y. Ma, H. Zhu, Y. Hu, C. Xiao, X. Yi, G. Zhu, H. Lv, L. Ma, T. Chen, Z. Tie, Z. Jin and J. Liu, J. Am. Chem. Soc., 2016, 138, 15829-15832.

16 G. Grancini, C. Roldán-Carmona, I. Zimmermann, E. Mosconi, X. Lee, D. Martineau, S. Narbey, F. Oswald, F. De Angelis, M. Graetzel and M. K. Nazeeruddin, Nat. Commun., 2017, 8, 15684.
17 D. Shi, V. Adinolfi, R. Comin, M. Yuan, E. Alarousu, A. Buin, Y. Chen, S. Hoogland, A. Rothenberger, K. Katsiev, Y. Losovyj, X. Zhang, P. A. Dowben, O. F. Mohammed, E. H. Sargent and O. M. Bakr, Science, 2015, 347, 519-522.

18 S. D. Stranks, G. E. Eperon, G. Grancini, C. Menelaou, M. J. Alcocer, T. Leijtens, L. M. Herz, A. Petrozza and H. J. Snaith, Science, 2013, 342, 341-344.

19 G. Xing, N. Mathews, S. Sun, S. S. Lim, Y. M. Lam, M. Gratzel, S. Mhaisalkar and T. C. Sum, Science, 2013, 342, 344-347.

20 S. G. Hashmi, D. Martineau, M. I. Dar, T. T. T. Myllymaki, T. Sarikka, V. Ulla, S. M. Zakeeruddin and M. Gratzel, J. Mater. Chem. A, 2017, DOI: 10.1039/c7ta04132b.

21 F. Huang, D. Chen, Y. Chen, R. A. Caruso and Y.-B. Cheng, J. Mater. Chem. C, 2014, 2, 1284-1289.

22 H. C. Weerasinghe, P. M. Sirimanne, G. P. Simon and Y.-B. Cheng, Prog. Photovoltaics Res. Appl., 2012, 20, 321-332.

23 M. Hu, L. Liu, A. Mei, Y. Yang, T. Liu and H. Han, J. Mater. Chem. A, 2014, 2, 17115-17121.

24 J. Burschka, N. Pellet, S. J. Moon, R. Humphry-Baker, P. Gao, M. K. Nazeeruddin and M. Gratzel, Nature, 2013, 499, 316319.

25 A. Binek, F. C. Hanusch, P. Docampo and T. Bein, J. Phys. Chem. Lett., 2015, 6, 1249-1253. 